\title{
Komunikasi Lingkungan dalam Budaya Masyarakat (Analisis Model Pesan Two Way Asymmetrical pada Lembaga Adat)
}

\author{
Dhanurseto Hadiprashada, Dwi Aji Budiman \\ Fakultas Ilmu Sosial dan Ilmu Politik, Universitas Bengkulu \\ Jl.W.R.Supratman, Kandang Limun, Kota Bengkulu, Bengkulu 38371 \\ hadiprashada@unib.ac.id, dabudiman@unib.ac.id
}

Masuk tanggal : 08-11-2019, revisi tanggal : 09-12-2019, diterima untuk diterbitkan tanggal : 11-12-2019

\begin{abstract}
The lack of documentation related to the potential of cultural values on the island of Sumatra provides obstacles for the community. This case especially happen in the pattern of delivering messages in the communication process. This condition provides a lot of intepretation to understanding about regulations related of cultural values. Therefor these obstacles can occur at various levels. It can be seen in the regulation of the government system, at the district and provincial level, and traditional institutions in each province. This study aims to examine the related message of two way asymmetrical message model in creating synergy in environmental communication patterns in the cultural wisdom of the people in Bengkulu province. This research was conducted using a case study approach in qualitative research. Collecting data procedure used in this study was purposive sampling, which is taking all information in research within accordance certain criteria, using purposive sampling. In-depth interviews were conducted with informant in the goverment institution we call it Badan Musyawarah Adat (BMA) and independen traditional institution, Aliansi Masyarakat Adat Nusantara (AMAN) in the Bengkulu region, which is a community organization focused on issues of customs and culture. The results show that the two way asymmetrical message model that occurs in one process, can actually create a pattern of relationships between the environment, and communication. This message model directly sees the environment as an important object. The environment becomes a model for the formation of messages that are informative for the community in carrying out activities related to the information they are receiving. The process of studying messages, the cultural values of society can actually revitalize the culture itself in the process of forming the message that has been conveyed. This is what causes the symbolic meaning in the wisdom of communication in the community environment.
\end{abstract}

Keywords: culture, communication, environment, messages, values

\begin{abstract}
Abstrak
Belum terdatanya seluruh potensi nilai budaya di Pulau Sumatera secara khusus memberikan hambatan tersendiri bagi masyarakat. Khususnya dalam pola penyampaian pesan dalam proses komunikasi. Kondisi ini memberikan banyak ruang dalam pemahaman atas regulasi terkait nilai budaya tersebut. Hambatan ini dapat terjadi dalam berbagai tingkatan. Seperti dalam regulasi sistem pemerintahan, di tingkat kabupaten, provinsi dan pada lembaga-lembaga adat yang ada di setiap provinsi. Penelitian ini bertujuan untuk melakukan kajian terkait model pesan dalam menciptakan sinergisitas
\end{abstract}


pola komunikasi lingkungan dalam kearifan budaya masyarakat di Provinsi Bengkulu. Penelitian ini dilakukan dengan menggunakan pendekatan studi kasus dalam penelitian kualitatif. Prosedur pengambilan data yang digunakan dalam penelitian ini adalah purposive sampling, yaitu mengambil semua informasi yang sesuai dengan kriteria tertentu, dengan menggunakan pengambilan sampel bertujuan (purposive sampling). Wawancara mendalam dilakukan kepada informan yaitu, Badan Musyawarah Adat, (BMA) yang menangani permasalahan adat istiadat di Provinsi Bengkulu dan Aliansi Masyarakat Adat Nusantara (AMAN) wilayah Bengkulu yang merupakan organisasi masyarakat yang fokus dalam masalah adat dan budaya. Hasil penelitian menunjukkan bahwa model pesan two way asymmetrical yang terjadi dalam satu proses, ternyata dapat menciptakan pola hubungan antara lingkungan, dan komunikasi. Model pesan ini secara langsung melihat lingkungan menjadi sebuah objek yang penting. Lingkungan menjadi sebuah model pembentukan pesan yang bersifat informatif bagi masyarakat dalam menjalankan aktivitas terkait informasi yang sedang mereka terima. Proses pada telaah pesan, nilai- nilai budaya masyarakat ternyata dapat merevitalisasikan budaya itu sendiri dalam proses pembentukan pesan yang telah tersampaikan. Hal ini yang menyebabkan adanya pemaknaan simbolik dalam kearifan komunikasi dalam lingkungan masyarakat.

Kata Kunci: budaya, komunikasi, lingkungan, nilai, pesan

\section{Pendahuluan}

Kondisi pendokumentasian nilai budaya yang masih sangat minim banyak terjadi di provinsi yang ada di Pulau Sumatera. Pendokumentasian ini terkait masih belum terdatanya seluruh potensi yang dimiliki. Kurangnya dokumen akademik terkait sistem nilai yang berlaku di setiap Provinsi menjadikan pola penyampaian pesan kepada khalayak tidak maksimal. Celah ini kemudian bisa berevolusi dalam berbagai bentuk, salah satunya dengan minimnya pemahaman atas regulasi dan nilai- nilai budaya lokal yang ada di daerah tersebut. Adanya pergeseran nilai budaya dan masuknya budaya lain memberikan dampak tersendiri bagi masyarakat. Prayogi, R. dan Danial, E. (2016 ) dalam pernyataannya memberikan gambaran perkembangan cyber space, internet, informasi elektronik dan digital, ditemui dalam kenyataan sering terlepas dari sistim nilai dan budaya. Kondisi pembangunan yang tidak seimbang dalam lingkungan masyarakat ini yang kemudian menjadi menarik untuk diamati. Tumbuh pembangunan yang bersifat fisik seolah-olah tidak memberikan ruang dalam penataan sistem nilai yang ada di Indonesia, tidak terkecuali bagi daerahdaerah yang baru akan berkembang.

Fenomena ini kemudian secara berkelanjutan memberikan kekuatan bagi penggiat budaya lokal dalam mendokumentasikan sistem nilai budaya yang dimiliki oleh masing-masing wilayah, khususnya yang ada di Sumatera. Proses ini dapat dilihat dari beberapa kajian yang dilakukan beberapa wilayah yang sedang mencoba menyusun nilai-nilai budaya yang ada. Penelitian Qanun di Aceh, Natsir, M., dan Rachmad, A. (2019) mencoba mengintepretasikan Pasal 1 angka 6 dan angka 7 Qanun PLH bahwa Lingkungan hidup yang merupakan kesatuan ruang dengan semua benda, daya, keadaan, dan makhluk hidup, termasuk manusia dan perilakunya, yang mempengaruhi alam itu sendiri, kelangsungan peri kehidupan, dan kesejahteraan manusia serta makhluk hidup lainnya. Penelitian 
tersebut secara khusus menurut mereka sangat penting untuk memasukan kearifan lokal yang dalam pengaturan Qanun Pengelolaan lingkungan hidup (PLH) yaitu diyat atau dheit dan sayam. Selanjutnya, fenomena pembangunan terkait penerapan nilai- nilai adat yang ada di Provinsi Bengkulu ini secara khusus pernah dilakukan oleh beberapa peneliti. Osira.Y (2015), secara khusus pernah melakukan penelitian terkait Jaringan Sosial Rajo Penghulu dalam Penanganan Masalah Sosial sebagai Perwujudan Implementasi Perda Kota Bengkulu Nomor 29 Tahun 2003. Hasil penelitian menunjukkan bahwa jaringan sosial perlu dilakukan karena tidak semua lembaga sosial termasuk Rajo Penghulu di beberapa wilayah di Kota Bengkulu belum mampu memenuhi kebutuhan atau memecahkan masalahnya sendiri, sehingga perlu mengakses sumber-sumber dan menjalin kemitraan dengan lembaga atau organisasi lainnya. Kajian yang dilakukan tersebut, meletakkan fokus hasil penelitian pada belum adanya manifestasi bentuk penganggaran bagi operasional lembaga adat, maupun insentif bagi pengurus lembaga adat khususnya dalam pengelolaan lingkungan. Selanjutnya, Hadiprashada, D., et al (2018) menemukan bahwa, secara khusus pemerintah daerah Kabupaten Bengkulu Utara, Provinsi Bengkulu belum mengakomodir nilai- nilai asli masyarakat adat yang di Kepulauan Enggano dalam berbagai regulasi di tingkat daerah, khususnya dalam pengelolaan wisata berbasis keragaman hayati di Pulau Enggano.

Hal inilah yang kemudian menjadikan nilai-nilai adat dan budaya pada masyarakat di Provinsi Bengkulu menjadi menarik untuk terus disikapi. Permasalahan terkait nilai-nilai adat pada masyarakat yang ada di Provinsi Bengkulu menjadi penting untuk ditelaah dalam berbagai sudut pandang, salah satunya dengan pendekatan dalam komunikasi pembangunan berbasis lingkungan. Berdasarkan hasil kajian dan penelitian yang telah dilakukan oleh peneliti terdahulu, masih banyak terjadi hambatan dalam berbagai proses yang dilakukan. Tidak hanya pada sistem pemerintahan di tingkat kabupaten dan Provinsi, masalah ini juga terjadi pada lembaga-lembaga adat yang ada.

Rumusan masalah dalam penelitian ini ingin mengkaji bagaimana nilainilai adat pada masyarakat yang ada di Provinsi Bengkulu dapat bersinergi dengan pola komunikasi lingkungan dalam kearifan masyarakat. Tujuan dari penelitian yang dilakukan ini untuk melakukan analisis model pesan two way asymmetrical pada Lembaga Adat dalam menyampaikan pesan komunikasi lingkungan yang terdapat dalam nilai-nilai adat masyarakat. Fenomena ini secara khusus akan ditelaah menggunakan model pesan two way asymmetrical yang diharapkan dapat berkembang dalam konsep revitalisasi pada pola komunikasi lingkungan.

Konsep teori yang digunakan dalam penelitian ini mengacu kepada konsep komunikasi pembangunan berbasis lingkungan. Secara makro, komunikasi pembangunan menjadi sebuah terobosan dalam lingkup ilmu sosial dan menjelma menjadi sebuah inovasi yang termodifikasi dalam berbagai bentuk media sehingga dianggap mampu menjangkau semua komunitas dengan segala fungsinya (Hadiprashada, et.al. 2016). Konsep ini kemudian berkembang ketika pada banyak referensi dijelaskan bahwa berbagai model teoritis dapat digunakan dalam merancang strategi komunikasi untuk pembangunan (Hadiprashada, et.al. 2016). Strategi dalam pencapaian ini pun tentunya dapat disesuaikan dengan kondisi 
sosial masyarakat setempat tujuan. Servaes, (2008) justru melihat bahwa proses ini dapat di identifikasi dan dapat disesuaikan dalam organisasi yang bekerja di tingkat masyarakat dengan kondisi geografis yang berbeda.

Gagasan ini secara khusus dapat terlihat dalam pola komunikasi yang dilakukan oleh masyarakat dalam membentuk pola komunikasi lingkungan sebagai sebuah bentuk tindakan simbolik dalam lingkungannya. Cox (2013) melihat bahwa terjadi pola hubungan antara lingkungan, komunikasi, dan ruang publik (public sphere). Pola ini melihat lingkungan menjadi sebuah isu pokok dalam masyarakat dan lingkungan dapat dijadikan sebuah bentuk persepsi atas sebuah perilaku untuk melaksanakan atau menjalankan sesuatu. Gagasan ini tentunya akan terwujudnya apabila masyarakat mengerti bagaimana dampak ini akan dikomunikasikan. Asumsi di tingkat micro dari gagasan ini dengan melihat bahwa khalayak dapat meminta informasi pembangunan, membuat kesepakatan untuk pengembangan dan meminta solusi atas masalah-masalah pembangunan (Kumar, 2011). Prasyarat dalam perspektif ini dengan melihat sumber daya manusia dan pendekatan lokal dikonstruksikan dalam strategi komunikasi pembangunan berbasis lingkungan. Perspektif ini yang kemudian menjadi telaah teoritis dalam membingkai komunikasi lingkungan melalui model pesan two way asymmetrical pada lembaga adat yang ada di provinsi Bengkulu.

Model pesan yang disampaikan oleh Grunig dan Hunt (1984) melahirkan prinsip dasar dalam penerapan pesan budaya masyarakat. Pola pesan dalam proses komunikasi ini mengandung dua unsur yaitu, inisiasi komunikasi dan pengembangan hubungan. Pengembangan hubungan masih berpusat pada sumber, dan tentu saja dapat bersifat satu arah maupun dua arah. Oleh karenanya, aktivitas komunikasi ini tentunya ditujukan agar khalayak menerima keputusan, terbuka, dan dapat bekerja sama dengan organisasi. Hal ini yang kemudian menjadi kata kunci dalam pengembangan kajian model pesan dalam penelitian ini.

\section{Metode Penelitian}

Metode penelitian yang digunakan dalam penelitian ini dilakukan dengan menggunakan pendekatan studi kasus dalam kualitatif. Prosedur pengambilan data yang digunakan dalam penelitian ini adalah purposive sampling, yaitu mengambil semua informasi yang sesuai dengan kriteria tertentu, dengan menggunakan pengambilan sampel bertujuan (purposive sampling) dalam riset eksplorasi atau riset lapangan (Neuman, 2003). Pengamatan langsung difokuskan pada kinerja dan agenda program dari masing-masing objek yang akan diteliti. Sedangkan wawancara mendalam (in-depth interview) dilakukan kepada informan yaitu, perangkat lembaga Badan Musyawarah Adat (BMA) Provinsi Bengkulu yang merupakan lembaga pemerintah di tingkat provinsi yang fokus dalam permasalahan adat istiadat dan Ketua Aliansi Masyarakat Adat Nusantara (AMAN) wilayah Bengkulu yang merupakan organisasi sosial kemasyarakatan independen dalam bidang adat dan budaya. Wawancara yang dilakukan tidak dalam suasana formal dan bisa dilakukan lebih satu kali wawancara pada satu informan. 
Penelitian ini menggunakan teknik analisa kualitatif deskriptif di mana data yang di peroleh berupa literasi yang didapat dari pengamatan langsung dan wawancara. Tahapan analisis data kualitatif dilakukan dengan melakukan reduksi data sesuai fokus penelitian dengan cara menyederhanakan dan mengambil inti dari data dari nilai-nilai budaya yang dilakukan oleh Badan Musyawarah Adat (BMA) dan Aliansi Masyarakat Adat Nusantara (AMAN) dengan triangulasi sumber data. Penyajian data yang disajikan tekait dengan pemaknaan pesan nilai budaya yang menjadi fokus dari lembaga adat yang ada. Penarikan kesimpulan dilakukan berdasarkan temuan data dan analisis model dari pola komunikasi dan lingkungan.

\section{Hasil Penemuan dan Diskusi}

\section{Model Pesan Two Way Asymmetrical Pada Lembaga Adat Di Provinsi Bengkulu}

Pemetaan dan pendeskripsian nilai adat yang dimiliki oleh masyarakat adat yang ada di provinsi Bengkulu ini di dasarkan atas dua hal. Pertama, kondisi adat istiadat, budaya dan kedua lingkungan itu sendiri. Pemisahan fungsi ini secara khusus terjadi dalam aktivitas yang dilaksanakan oleh lembaga adat pemerintah atau Badan Musyawarah Adat (BMA) dan lembaga adat masyarakat dalam bentuk organisasi masyarakat Aliansi Masyarakat Adat Nusantara (AMAN).

Secara khusus, BMA memberikan akses bagi masyarakat untuk menjalankan adat istiadat yang menjadi dasar dalam norma keseharian yang dijalani. Adat sebagai dasar dalam bertindak, memiliki beberapa perbedaan dalam pendefinisian makna. Seperti pendefinisian makna dalam Peraturan Daerah Kota Bengkulu No. 29 Tahun 2003 tentang pemberlakukan adat Kota Bengkulu. Pasal 1 dalam Perda tersebut mendefinisikan Adat Kota Bengkulu merupakan adat Lembak, adat Melayu, adat Serawai, dan adat Rejang. Pola pendefinisian ini menjadi sangat berbeda dari penafsiran adat yang dimiliki oleh masing-masing entitas suku yang ada tersebut. Wawancara yang dilakukan kepada Ketua BMA Provinsi Bengkulu, didapatkan hasil bahwa,

Adat istiadat yang ada di kota Bengkulu ini sebenarnya akar sumbernya itu kalau dilihat dari historisnya sudah berkembang sejak lama. Jadi pada saat berkembangnya perdagangan yang ada di Bengkulu atau Bencoolen pada tempo itu sangat berkembang dengan baik. Dan terjadi beberapa akulturasi budaya yang ada di Bengkulu, terkhusus di kota Bengkulu karena adanya di kota...

Berdasarkan hasil wawancara yang telah dilakukan, BMA Provinsi Bengkulu memiliki kecenderungan memberikan pemaknaan pesan yang bersifat formal. Hal ini sesuai dengan Peraturan Daerah Kota Bengkulu No. 29 Tahun 2003 tentang pemberlakukan adat Kota Bengkulu. Konsep nilai-nilai adat yang mengarah ke dalam bentuk kearifan lingkungan tidak muncul dalam pengembangannya. Persepsi inilah yang menimbulkan asumsi bahwa BMA yang ada di Provinsi Bengkulu hanya melihat adat istiadat dalam bentuk kegiatan yang bersifat ceremonial (upacara) seperti dalam kelahiran, pernikahan, kematian, dan 
musyawarah adat warga sekitar dan beberapa festival budaya yang dilakukan oleh pemerintah daerah.

Temuan tersebut berbeda dengan pola pendokumentasian nilai-nilai adat yang dilakukan Aliansi Masyarakat Adat Nusantara (AMAN) Wilayah Bengkulu. Konsep pengembangan nilai-nilai adat yang coba diinisiasi oleh Organisasi Sosial ini memberikan beberapa pilihan kepada masyarakat untuk ikut berperan aktif dalam pengembangan nilai budaya dan adat istiadatnya dalam berbagai bentuk. Berdasarkan pengamatan partisipatif yang telah dilakukan, AMAN telah berhasil menginisiasi produk hukum dalam bentuk Peraturan Daerah Kabupaten Rejang Lebong No. 5 Tahun 2018 tentang Pengakuan dan Perlindungan Masyarakat Hukum Adat (PPMHA) di Kabupaten Rejang Lebong, Provinsi Bengkulu. Perda ini secara khusus memberikan kesempatan bagi masyarakat adat untuk mengembangkan keberlanjutan lingkungannya sesuai dengan nilai-nilai adat dan budaya yang telah berlaku turun menurun. Hal ini yang kemudian memberikan ruang dalam proses komunikasi yang berimbang dalam masyarakat, Negara, dan pemerintah.

Berdasarkan hasil pengamatan yang muncul dari objek penelitian yang coba di telaah oleh penulis, terdapat pola yang unik dalam penerapan model pesan two way asymmetrical yang muncul. Model pesan ini secara khusus dapat didefinisikan sebagai "persuasi ilmiah" (Grunig \& Hunt, 1984). Konsep ini secara khusus melihat lembaga adat sebagai fungsi yang yang berperan sebagai agen perubahan dalam masyarakat. Pada data hasil pengamatan yang telah dilakukan, BMA memiliki kecenderungan mengkonstruksikan pengetahuan yang dimilikinya untuk kemudian disusun dalam sebuah konsep peraturan dan norma adat. Sehingga konsep ini kemudian ditularkan dalam skema terkait sikap dan perilaku untuk meyakinkan publik atau masyarakat untuk mengakui pandangan dari lembaga ini. Safruddin Wahid (2014) dalam Panuju, R. dan Narena, I. Kadek. (2019), memberikan gambaran bahwa gaya komunikasi dapat disesuaikan dengan situasi dan kondisi yang ada. Kondisi ini terkait tingkat kepercayaan yang tinggi terhadap organisasi, maka gaya komunikasi yang cenderung memberi ganjaran berupa pujian sangat dibutuhkan, sebaliknya di suatu organisasi yang cenderung loyalitas berkurang maka gaya otoritarian acapkali dibutuhkan untuk menegakkan kedisiplinan (Panuju \& Kadek, 2019). Kondisi ini memberikan sebuah skema dalam melihat hubungan model komunikasi dengan gaya berkomunikasi yang terjadi pada organisasi Badam Musyawarh Adat (BMA) provinsi Bengkulu. Konstruksi pengetahuan nilai budaya yang dimiliki selalu menjadi pijakan dalam membangun kondisi sosial di dalam masyarakat maupun organisasi tersebut. Bakti, I. et al (2017) memberikan pandangan bahwa dinamika sosial dalam suatu wilayah dapat dilihat dari berfungsi tidaknya organ/struktur/lembaga kemasyarakatan dalam melayani tuntutan sosial yang ada di wilayah tersebut. Apabila lembaga atau organisasi tersebut berfungsi dengan baik, maka lembaga atau organisasi tersebut akan mampu menciptakan daya dukung dalam perjalanannya.

Hal ini yang menjadi unik dalam penerapan model pesan assymetrical, jika persuasi dalam model asimetris dua arah lebih bersifat ilmiah, persuasi dalam agen pers / model humas lebih bersifat intuitif, artinya terjadi pola komunikasi 
yang bersifat top down dalam proses distribusi informasi. Hal ini jelas sangat bernegasi dalam model ini. Alur dalam model ini melahirkan konsep atau ide yang dapat muncul dan masuk ke pikiran audiens sekaligus akan menyesuaikan pesan untuk mendapatkan reaksi yang paling efektif (Grunig \& Hunt, 1984).

Kondisi tersebut sangat berbeda dengan yang terjadi pada lembaga adat masyarakat (independent) dalam bentuk organisasi masyarakat Aliansi Masyarakat Adat Nusantara (AMAN). AMAN dalam konsep ini menjadi sebuah media dalam proses komunikasi antara organisasi, pemerintah dan publik (masyarakat). Pada tahap ini AMAN mencoba untuk mengkonstruksikan pesan yang ada di akar rumput (masyarakat) menjadi sebuah sistem yang di akui dan dijalankan secara bersama sama. Proses ini menurut Pimpinan Wilayah AMAN Bengkulu, bahwa,

Proses penggalian data-data budaya ini kami mulai secara bertahap, dengan mengajak masyarakat adat yang ada, kemudian mulai menggali latar belakang kesejarahan, sosial, budaya, yang disusun berdasarkan kaidah ilmiah dalam bentuk riset etnografi, survey khalayak, dan pembuatan naskah akademik. Proses ini tentunya melibatkan seluruh komponen masyarakat yang ada di wilayah tersebut sehingga peran partisipasi masyarakat, pemerintah, dan organisasi lain sangat terlihat dalam setiap tahapan proses yang kami coba inisiasi.

Jika dianalisis menggunakan model pesan assymetrical, Grunig dan Hunt menjelaskan bahwa model ini ditujukan dalam rangka menghasilkan sikap saling pengertian (dialog) dalam setiap proses perencanaan dan evaluasi hubungan masyarakat. Konsep ini jika divisualkan, dapat dipisahkan menjadi 2 konsep, Secara khusus Pada dasarnya, empat model hubungan masyarakat dapat dipisahkan menjadi dua konsep, yaitu komunikasi satu arah (one way communication) atau komunikasi dua arah (two way communication), dan komunikasi simetris atau asimetris.

Tabel 1. Grunig dan Hunt

\begin{tabular}{lll} 
& one way communication & two way communication \\
\hline Asymmetric & Press Agentry/ & Two-way asymmetric \\
& Publicity Model & Model \\
\hline Symmetric & Public Information & Two-way symmetric \\
& Model & Model \\
\hline
\end{tabular}

Pola ini yang kemudian menjadi transformasi dalam penerapan model pesan yang disampaikan oleh Grunig dan Hunt. Secara khusus model pesan ini melahirkan prinsip dasar dalam penerapan pesan budaya masyarakat. Pola pesan dalam proses komunikasi inilah yang muncul pada lembaga adat non pemerintah di provinsi Bengkulu. Inisiasi penyeimbang dalam penerapan pesan budaya yang dibawa oleh Aliansi Masyarakat Adat Nusantara (AMAN) mampu menciptakan data kesejarahan dalam sistem sosial dan budaya masyarakat adat dalam pengelolaan lingkungan yang tertuang dalam proses Perda yang sudah tercipta. 


\section{Revitalisasi Nilai Adat dalam Komunikasi Lingkungan}

Revitalisasi dalam nilai adat berdasarkan Undang Undang Nomor 5 tahun 2017 tentang Pemajuan Kebudayaan dapat dimaknai sebagai upaya menghidupkan kembali objek pemajuan kebudayaan yang telah atau hampir musnah. Hal ini yang menjadikan proses transformasi pesan dalam model assymetrical dapat menjadi pijakan dalam pengembangan konsep dalam komunikasi lingkungan. Konsep penyeimbang dalam penerapan pesan budaya yang dibawa oleh Aliansi Masyarakat Adat Nusantara (AMAN) memberikan bentuk tindakan simbolik pada masyarakat yang mengikutsertakan nilai-nilai kearifan dalam hubungan mereka dengan lingkungan.

Tabel 2. Modifikasi model pesan Grunig dan Hunt

\begin{tabular}{lll} 
& One way communication & two way communication \\
\hline Asymmetric & Press Agentry/ & Two-way asymmetric \\
& Publicity Model & Model \\
\hline Symmetric & Public Information & Two-way symmetric \\
& Model & Model \\
\hline & Environmental & Two-way asymmetric \\
& Communication & Model \\
\hline
\end{tabular}

Model pesan two way asymmetrical pada lembaga adat dalam menyampaikan pesan komunikasi, perlahan bergeser dan menciptakan konsep yang berbeda dalam pemaknaan simbolik dalam lingkungannya. Konsep kutei yang ada di Kabupaten Rejang Lebong, dimaknai sebagai kesatuan wilayah adat dalam satu sistem budaya. Kutei ini didirikan berdasarkan peraturan yang disepakati bersama warga kutei. Ruang lingkup kutei meliputi hubungan dengan warga Kutei, dengan alam sekitar, bahkan dengan lingkungan metafisik. Pelaksanaan keseharian dalam Kutei ini mampu memberikan rambu-rambu dalam pemanfaatan air dan wilayah sekitarnya seperti dusun sekitar (sadei). Zona pemeliharaan pun disusun berdasarkan nilai-nilai adat yang berkembang pada masyarakat adat ini seperti, aturan dalam penggunaan mata air (ulue tulung), taneak tanei (tanah), dan imbo bano (hutan/alam) yang tentunya merupakan sumber daya bagi masyarakat. Pemaknaan simbolik manusia mengenai lingkungannya merupakan titik tekan utama dalam keilmuan komunikasi, terutama komunikasi lingkungan (Yenrizal, et al, 2015). Sejalan dengan hal tersebut, penjelasan dalam tabel 2, terkait model pesan yang bisa terjadi dalam satu proses, ternyata dapat menciptakan pola hubungan antara lingkungan (nature/environment), dan komunikasi (communication).

Model pesan ini secara langsung melihat lingkungan (environmental) menjadi sebuah objek yang penting. Lingkungan menjadi sebuah model pembentukan pesan yang bersifat informatif bagi masyarakat dalam menjalankan sesuatu terkait informasi yang sedang mereka terima. Kehadiran pesan yang bersifat informatif memberikan peluang untuk menciptakan ruang publik dalam kemasan nilai-nilai budaya. Hal ini menurut Tjiook, W. (2017), bisa memberikan dorongan dalam memberdayakan masyarakat dan menyatukan orang-orang dengan latar belakang budaya yang beragam, mengatur panggung untuk interaksi sosial yang positif dalam memaknai lingkungannya. Pemaknaan akan nilai-nilai 
budaya inilah yang kemudian dapat menjadi embrio dalam upaya merevitalisasi kearifan nilai budaya dalam konsep komunikasi lingkungan.

\section{Simpulan}

Berdasarkan pembahasan masalah diatas, dapat disimpulkan bahwa, model pesan two way asymmetrical pada Lembaga Adat dalam menyampaikan pesan komunikasi memiliki perbedaan dalam objek penerapannya. Pada telaah pesan, nilai- nilai budaya masyarakat ternyata dapat merevitalisasikan budaya itu sendiri dalam proses pembentukan pesan yang telah tersampaikan. Hal ini yang menyebabkan adanya pemaknaan simbolik dalam kearifan komunikasi dalam lingkungan masyarakat. Penerapan model ini tentunya akan menemukan perbedaan dalam setiap proses, analisis dan intepretasi data yang akan ditulis. Sehingga dibutuhkan penelitian lanjutan dalam upaya pembentukan model dalam pesan yang akan ditelaah dalam sudut pandang ilmu komunikasi.

\section{Ucapan Terima Kasih}

Ucapan terima kasih penulis tujukan kepada seluruh narasumber yang telah bersedia untuk bekerja sama selama penelitian ini berlangsung. Terima kasih juga disampaikan kepada Fakultas Ilmu Sosial dan Ilmu Politik, Universitas Bengkulu yang telah memberikan dana hibah penelitian, sehingga penelitian ini dapat terlaksana. Selanjutnya, kami haturkan terima kasih kepada Dewan redaksi Jurnal Komunikasi, Fakultas Ilmu Komunikasi Universitas Tarumanagara yang berkenan memberikan review atas hasil dari penelitian ini.

\section{Daftar Pustaka}

Bakti, I., Hafiar, H., Budiana, Riyanto, H., Puspitasari, L. (2017). Pemberdayaan Pranata Sosial Melalui Komunikasi Lingkungan: Menakar Pelibatan Peran Perempuan Dalam Mitigasi Banjir Citarum. Kawistara, 7(1), 94-107. https://doi.org/10.22146/kawistara.24313

Cox, R. (2013). Environmental Communication and the Public Sphere, $3^{\text {rd }}$ ed. USA: Sage.

Grunig E. James., and Hunt, Todd. (1984). Managing Public Relations. Austin, United States: Halt, Rinehart and Winston.

Hadiprashada, D., Budiman, D. A., \& Saragih, R. B. (2018). Revitalization of Cultural Value System (Mapping of Indigeneous Culture and Value System in Enggano Island Indonesia). The International Journal of Social Sciences and Humanities Invention, 5(9), 49824985. https://doi.org/10.18535/ijsshi/v5i9.05

Hadiprashada, D., Guntoro, B., Mudiyono., \& Subejo. (2016). Kearifan Larangan Jurai dalam Peristiwa Tutur dan Tindakan Tutur Masyarakat; Catatan Etnografi Masyarakat Napal Hijau dalam Melestarikan Kawasan Bukit Kumbang, Muara Sahung Kabupaten Kaur, Provinsi Bengkulu. Yogyakarta, Indonesia: Pustaka Pelajar. 
Kumar, R. (2011). Development Communication: A Purposive Communication With Social Conscience-An Indian Perspective. Global Media Journal: Indian Edition, 2(2).

Natsir, Muhammad \& Rachmad, Andi. (2019). Penetapan Asas Kearifan Lokal Sebagai Kebijakan Pidana dalam Pengelolaan Lingkungan Hidup di Aceh. Jurnal Magister Hukum Udayana (Udayana Master Law Journal), 7(4), 468-489. https://doi.org/10.24843/JMHU.2018.v07.i04.p05

Neuman, Lawrence W. (2003). Social Reserch Methods. Qualitative and Quantitative Approaches, Fifth Edition. USA: Needham Heights, A Pearson Education Company

Osira, Yessilia. (2015). Jaringan Sosial Rajo Penghulu Dalam Penanganan Masalah Sosial (Sebagai Wujud Implementasi Peraturan Daerah Kota Bengkulu Nomor 29 Tahun 2003). Mimbar, 4(4), 37-43.

Panuju, R. dan Narena, I. Kadek. (2019). Komunikasi Organisasi Bidang Reservasi Hotel. Jurnal Komunikasi, 11(1), 30-41. http://dx.doi.org/10.24912/jk.v10i1.2297

Peraturan Daerah Kabupaten Rejang Lebong No. 5 Tahun 2018 tentang Pengakuan dan Perlindungan Masyarakat Hukum Adat (PPMHA) di Kabupaten Rejang Lebong, Provinsi Bengkulu

Peraturan Daerah Kota Bengkulu No. 29 Tahun 2003 tentang pemberlakukan adat Kota Bengkulu. Undang Undang Nomor 5 tahun 2017 tentang Pemajuan Kebudayaan

Prayogi, R. dan Danial, E. (2016). Pergeseran Nilai-Nilai Budaya Pada Suku Bonai Sebagai Civic Culture Di Kecamatan Bonai Darussalam Kabupaten Rokan Hulu Provinsi Riau. Humanika, 23(1), 61-79. https://doi.org/10.14710/humanika.23.1.61-79

Servaes, J., 2008, Communication for Development and Social Change. India: SAGE Publications.

Tjiook, W. (2017). Pecinan as an inspiration; The contribution of Chinese Indonesian architecture to an urban environment. Jurnal Wacana, 18(2). 556-580. http://dx.doi.org/10.17510/wacana.v18i2.596

Yenrizal, Rahmat, A., Bajari, A., Iskandar, J. (2015). Makna Simbolik Sawah di Masyarakat Pedesaan Tinjauan Komunikasi Lingkungan pada Masyarakat Semende Darat Tengah. Kawistara, 5(3), 287-297. https://doi.org/10.22146/kawistara.10057 